\title{
Evaluation of two mobile health apps for patients with breast cancer using the Mobile Application Rating Scale
}

\author{
Alexander Wright^^ \\ Institute of Healthcare Informatics, University College London, London, UK \\ Correspondence to: Alexander Wright, MBBS BSc (Hons). Institute of Healthcare Informatics, University College London, London, UK. \\ Email: alexander.wright.10@ucl.ac.uk.
}

\begin{abstract}
Background: Breast cancer is one of the most frequently diagnosed cancers worldwide. Screening, education about signs and symptoms, and improved access to treatment has helped reduce mortality. An understanding of the informational needs of women with breast cancer can help identify areas where mobile apps can further improve the experience of this patient group.

Methods: Personas are a commonly used tools in user centred design to help represent particular user archetypes. Knowledge of existing informational needs and prior research using personas in breast cancer app design were used to create two different personas through which to source apps for evaluation. The Mobile Application Rating Scale, a common evaluation framework, was used to evaluate the mobile apps across several important domains.

Results: Becca and OWise, two apps for breast cancer, were found through a discovery process in line with the personas described. Overall, both apps scored highly on the Mobile Application Rating Scale. Both apps had limited or no research to support their use in this patient group, and had issues related to data privacy. Becca scored particularly highly in domains related to accessibility while OWise's extensive range of features scored highly for functionality.

Conclusions: Both apps demonstrate the ability to fill an informational needs gap as evidenced in the existing literature. As with many mobile health apps, more clinical evidence and improved data handling would help support the widespread recommendation of their use in women who are undergoing or have completed treatment for breast cancer.
\end{abstract}

Keywords: Breast cancer; Mobile Application Rating Scale (MARS); mHealth

Received: 06 December 2020; Accepted: 26 March 2021; Published: 20 October 2021.

doi: $10.21037 /$ mhealth-20-161

View this article at: http://dx.doi.org/10.21037/mhealth-20-161

\section{Introduction \\ Epidemiology}

According to estimates of cancer incidence and mortality, breast cancer is the most frequently diagnosed cancer in 135 countries and the leading cause of cancer related mortality in over 100 (1). Globally, over 2 million cases of breast cancer are diagnosed each year, accounting for almost 1 in 4 cases of cancer in women. In the UK and the US, it is estimated that between 1 in 7 and 1 in 8 women will develop breast cancer in their lifetime $(2,3)$.

\section{UK breast cancer policy}

Earlier detection through screening has helped improve breast cancer mortality. The UK breast cancer screening programme was the first of its kind and began in 1988. Through the programme, women aged 50-70 can receive

^ ORCID: 0000-0001-7361-452X. 
Table 1 List of studies investigating the information needs of women with breast cancer

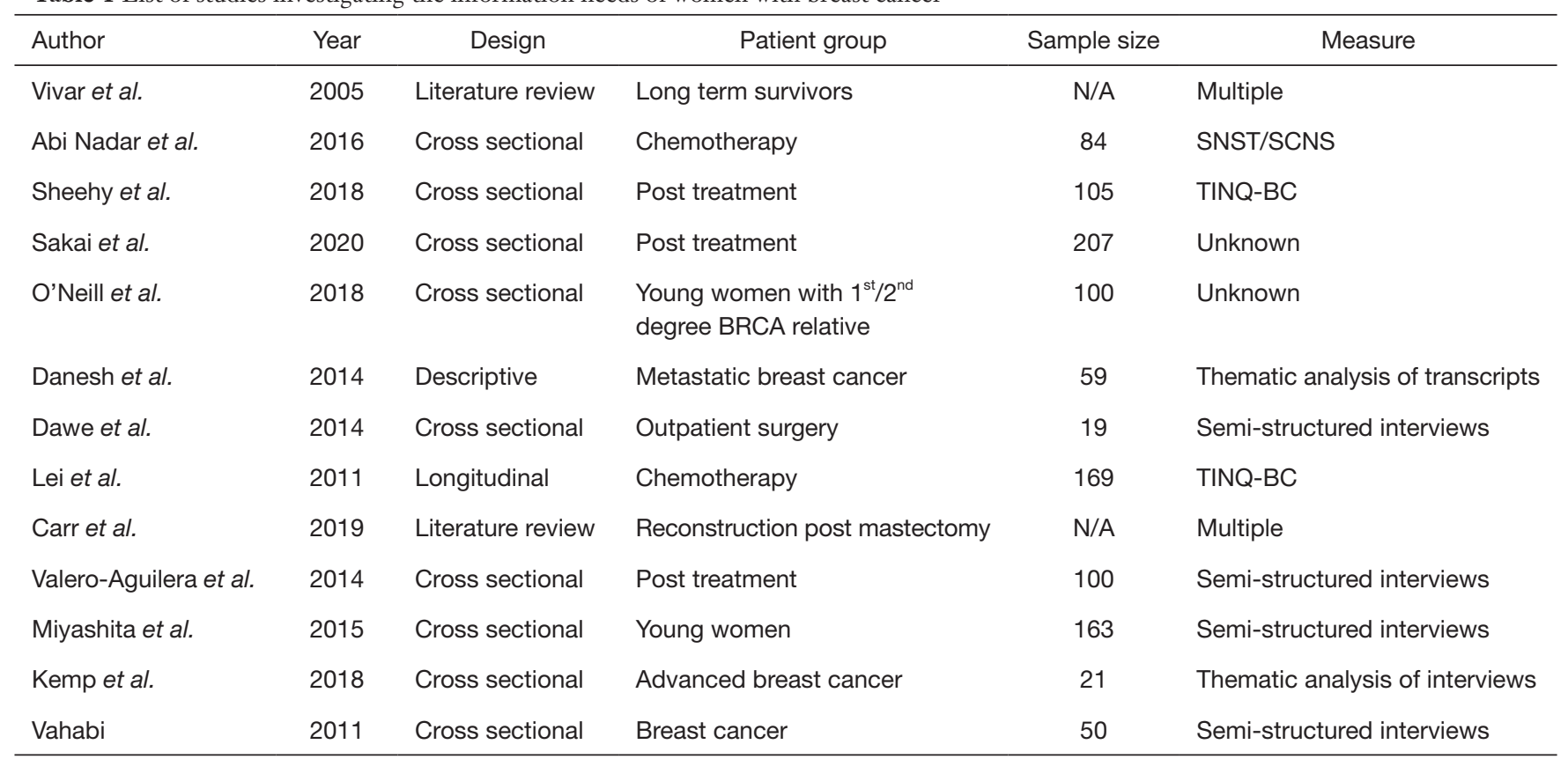

TINQ-BC, Toronto Informational Needs Questionnaire-Breast Cancer; SCNS, supportive care needs survey; SNST, supportive needs screening tool.

mammograms every 3 years (4).

In the last decade UK government and leading cancer charity policy has aimed to build on the success of the screening programme. Key policy themes include better education on symptoms and signs, improving lifestyles to reduce incidence, earlier diagnosis through screening, improving access to treatment, and enhancing patient experience and quality of life (5-8).

More recently, the NHS long term plan has advocated for more personalised therapeutic options and follow-up pathways for women diagnosed with breast cancer (9).

\section{Information needs}

National policy has to take a broad approach to cancerrelated interventions that may not account for the needs of specific patient sub-groups. Efforts have been made to investigate the information needs of women with breast cancer (Table 1). The majority of studies are crosssectional (10-18) with several literature reviews and metasyntheses $(19,20)$. The research is varied, investigating the information needs of women during and post treatment $(10-12,15,21)$. Some studies have focussed on younger women with breast cancer $(13,16)$, whilst others have focussed on long term survivors (19) and those managing advanced (17) and metastatic breast cancer (14).

Populations investigated were diverse including women from Lebanon (10), Ireland (11), Japan (12,16), America $(13,14)$, Canada (22), Malaysia (21), Spain (15), United Kingdom (23), Australia (17) and Iranian immigrants (18). Unfortunately, most studies used relatively small sample sizes ranging from 19 participants (22) to 207 (12) making the accuracy of the insights difficult to interpret.

Furthermore, validated questionnaires like the breast cancer version of the Toronto Informational Needs Questionnaire (TINQ-BC) were not commonly employed as part of the research methodology $(11,21)$ with many using bespoke questionnaires instead $(15,16,18)$.

Common findings from the studies reviewed included variation in information needs based on age $(10,16,19)$, a general preference to receive information directly from the healthcare provider $(10,12,17,20)$, and a desire for high-quality information related to recovery and prognosis $(11,14,15,20,21)$.

\section{Methods}

\section{Personas}

A common tool for both the design and evaluation of digital 
Persona 1 (post treatment)

Background

- 65 years old

- Married with two adult children

- Retired lawyer

- Underwent a total mastectomy

- Received post-operative radiotherapy

Attributes

- Has used health apps previously to help manage mental health

- Overwhelmed by number of online resources for breast cancer

- Expected more information to be provided by her oncologist

User needs

- Requires high quality information to help her cope following completion of her breast cancer treatment

- Would benefit from curated resources relevant for her specific concerns (which include loss of confidence in her body image

Persona 2 (receiving treatment)

Background

- 40 years old

- Long term partner, one teenage child

- Product manager

- Receiving neo-adjuvant chemotherapy

- Due for total mastectomy once chemotherapy completed

Attributes

- Uses multiple apps to track exercise and nutrition

- Struggling with chemotherapy side-effects including nausea, muscle ache and fatigue

- Doesn't feel has enough time to discuss concerns with her doctors or the nurses who administer her chemotherapy

User needs

- Ability to track her symptoms so she can easily share and discuss them with her clinical team

- A way to keep track of her chemotherapy courses so she can compare symptom severity between each round

Figure 1 Two personas describing the needs of different types of breast cancer patient. Persona 1 focuses on someone who has completed treatment whereas persona 2 focuses on a patient currently undergoing treatment.

health technology (DHT), and a key component of usercentred design, is the use of personas. Personas are an empirically derived user archetype (24) that can be used to communicate the key concerns, motivations and interests of a user group. These archetypes are developed through quantitative and qualitative user experience research and serve as a useful communication tool to help developers understand the needs of target users $(25,26)$.

Personas have been used extensively in the development of DHTs. Example patient groups include diabetics (27), older adults with heart failure (24), patients with coronary heart disease (28), multiple sclerosis (29), renal disease (30), children with cancer (31), women with gynaecological cancer (32), and older people generally (33).

It is beyond the scope of this study to undertake the qualitative and quantitative research to define persona archetypes for breast cancer patients. A review of the literature has identified several studies which have undertaken this process for specific DHT interventions.
One used a qualitative approach and focus group methodology to collect user needs and preferences for the content and features of a mobile app for arm and shoulder exercises after breast cancer treatment (34). Another similar qualitative research study using semi-structured interviews with breast cancer survivors explored user experiences and needs regarding rehabilitation and technology (35).

Based on these studies and the information needs for breast cancer patients described previously, it is possible to derive two broad archetypes for the purpose of finding appropriate DHTs to evaluate (Figure 1). These are patients who are currently undergoing treatment for breast cancer and those who have 'completed' treatment. The information requirements of these two groups are different. Those currently receiving treatment express a greater need for information related to treatment plans and side-effects (21), whilst those under long term follow up require help with social and physical rehabilitation $(12,15)$, and information related to prognosis (14). 
Table 2 Review number and overall rating taken from the Apple app store and Google Play store for both 'Becca' and 'OWise' (ratings collated on $22 / 11 / 20$ )

\begin{tabular}{lcccc}
\hline Name & $\begin{array}{c}\text { Number of iOS ratings } \\
\text { (all versions) }\end{array}$ & $\begin{array}{c}\text { Average iOS rating } \\
\text { (all versions) }\end{array}$ & $\begin{array}{c}\text { Number of Android ratings } \\
\text { (all versions) }\end{array}$ & $\begin{array}{c}\text { Average Android ratings } \\
\text { (all versions) }\end{array}$ \\
\hline Becca & 45 & $4.5 / 5$ & 78 & $4.4 / 5$ \\
OWise & 19 & $4.7 / 5$ & 18 & $4.6 / 5$ \\
\hline
\end{tabular}

\section{Evaluation frameworks}

Over 45 different mobile health app evaluation frameworks exist, created by a combination of academic institutions (36-39), non-profit organisations (40-42) and for-profit companies (43). Some frameworks focus on a specific type of health app such as mental health $(39,42,44)$, while others have more general use-cases. Criteria vary between frameworks, but common themes include data safety and privacy, app effectiveness, user experience, data integration, clinical relevance and credibility.

Several studies have attempted to review the myriad of different evaluation frameworks through systematic review. The results are not particularly reassuring, suggesting that many frameworks cannot be used unaltered and need to improve their assessments of possible user harm and the impact of software updates (45). There is also evidence to suggest that ratings provided by certain frameworks can be inconsistent and contradictory when assessing popular behavioural health apps (46).

For the purpose of this study, the Mobile Application Rating Scale (MARS) was used for app assessment. MARS is a popular framework and has been used in the evaluation of a variety of health apps including those for diabetes (47), gestational diabetes (48), renal disease (49), genitourinary tumours (50) and food allergies (51). Since its creation in 2015 it has been translated into other languages including Spanish (52) and German (53), and has been adapted for use by end-users of health apps (54). Evaluation of the MARS framework has shown good interrater reliability and internal consistency (38).

\section{Results}

\section{App selection}

The selection of two appropriate apps for assessment attempted to follow a discovery process in line with each of the personas described in figure 1 . Persona 1 had previously used the NHS Apps Library to find other health apps related to mental health. Following the same approach, searching for 'breast cancer' on the NHS app library returns the breast cancer app 'Becca' as the first result.

The description of 'Becca' ("Breast Cancer Now's Becca app provides specialist support to help you live with, through and beyond breast cancer"), is aligned with Persona 1's key characteristic of having completed their breast cancer treatment and requiring support in the post-treatment phase.

Persona 2 has a high level of technological literacy and is familiar with using mobile apps to track exercise and other aspects of her daily routine. Assuming persona 2 might take a more direct route to finding an appropriate resource for her needs, using the search query 'breast cancer tracker' within the Apple app store returns 'OWise' as the first result.

The description of 'OWise' (“...OWise gives you personalised, safe, reliable and credible information as well as practical support and guidance, in one easy-to-view place") also aligns well with the requirements of Persona 2, particularly as she is currently undergoing treatment for breast cancer.

\section{Evaluation results}

Table 2 shows the number of user reviews and overall rating of both apps from the Apple app store and the Google Play Store, while Table 3 shows the MARS results for both apps. Scores are provided against each section of the framework: engagement, functionality, aesthetics and information. Completed MARS assessments for both apps are included in Table S1. Scoring was carried out by the author.

Both apps have received consistently positive user reviews across the major app stores suggesting they meet user requirements and expectations to some degree. Although positive, the number of reviews for each app is limited, particularly for OWise. This is despite both apps being available for download for several years (3 years for Becca, 5 years for OWise) in the United Kingdom.

Neither app has a paid version with all functionality 
Table 3 Mobile App Rating Scale scores for breast cancer apps 'Becca' and 'OWise'

\begin{tabular}{lcccccc}
\hline Name & $\begin{array}{c}\text { Engagement } \\
\text { score }\end{array}$ & $\begin{array}{c}\text { Functionality } \\
\text { score }\end{array}$ & Aesthetics score & Information score & Mean score & Subjective score \\
\hline Becca & 3.6 & 5 & 4.7 & 4.2 & 4.38 & 3.75 \\
OWise & 4.2 & 5 & 4.7 & 4.3 & 4.55 & 4.75 \\
\hline
\end{tabular}

Each app is scored against multiple domains which also contributes to an overall mean score. MARS also allows for a subjective assessment which is included in the final column but does not contribute to the overall mean score. Application of rating scale carried out by author AW. Maximum score in any domain is 5 .

Available online the outset. OWise has a particular focus on physical health using predominantly monitoring and tracking functionality. Conversely, Becca is more multifaceted in its focus aiming to provide information and education on different topics relevant for women with breast cancer.

Both apps scored similarly overall. Within the subdomains of functionality and aesthetics, each app was able to demonstrate excellent performance, gestural design, navigation and ease of use, perhaps reflecting the fact that both products had been developed by professional agencies with a track-record in app design.

The apps differed in their engagement and information scores. For engagement, OWise's suite of features around tracking appointments, symptoms and treatment regimens made for a highly personalised and interactive experience. As a simple curator of high-quality breast cancer resources, Becca has less features to drive in-app engagement and is designed to direct users out of the app to relevant resources. Becca did have excellent accessibility features, allowing users to adjust screen size and zoom to suit their needs.

OWise scored marginally higher for the information section by virtue of having some, albeit limited, study literature to support its use in supporting women with breast cancer (55). A randomised clinical trial is underway, but results are yet to be reported. No supporting literature was found for Becca, however it was commissioned by a leading breast cancer charity and both apps have successfully gained access to the NHS Apps Library.

\section{Discussion}

Prior research investigating the effectiveness of breast cancer apps has consistently commented on the lack of a foundational evidence base to support their use. Several cross-sectional studies $(56,57)$ and systematic analyses (58-60) have called for more evidence of clinical effectiveness and safety to support breast cancer app use.
Of the two apps assessed here, only one (OWise) has made limited progress in this area, suggesting this is an ongoing issue in the realm of mobile health apps.

Becca does have the backing of a major UK breast cancer charity and aims to link users to high-quality information related to various aspects of breast cancer. However, research to evidence how these resources meet the information needs of women who have completed breast cancer treatment would be beneficial.

From a policy perspective, where personalisation in cancer care is being increasingly promoted (9), both apps aim to provide personalised experiences for their users. OWise has sophisticated symptom and treatment-tracking functionality whereas Becca can 'learn' what sort of breast cancer content any given user is most interested in for more personalised recommendations.

Accessibility is an important component of any DHT. Despite an excellent array of symptom and tracking functionality, OWise neglected to include simple accessibility features such as text enlargement and zoom capability which negatively impacted the engagement score. These features were present in Becca and should be viewed as a baseline requirement to ensure DHTs demonstrate a high level of inclusivity for a wide variety of users. Despite appropriate accessibility measures, Becca scored poorly for entertainment and interactivity. The app might benefit from added functionality, involving gamification or mood/ symptom tracking in order to drive engagement and maximise the benefit of its information resources.

Data privacy is an important domain through which to assess DHTs and is one of the more notable omissions of the MARS framework. Data related features have been explored by Orcha, which has carried out assessments of both the apps described here. Orcha rated the data privacy of Becca and OWise at $45.6 \%$ and $51.4 \%$ respectively, identifying some gaps in data encryption and a risk of identification through the data collected $(61,62)$.

Both apps seemed well suited to the specific user needs 
of the personas described in Figure 1. Unlike other health apps which aim to deploy one or more behaviour change techniques to impact a specific health behaviour, neither of the tools reviewed here had particular behavioural targets. However, they do address one of the key information needs of breast cancer patients-the provision of information by healthcare professionals. Becca provides an alternative source of high-quality information where this might be lacking from direct interactions with the patient's healthcare team, while OWise allows for the capture of key trends and data in order to facilitate better quality discussions with care providers. Becca also has a rich array of resources related to recovery and post-treatment care which was identified as a key information need in the existing literature.

Although both apps were consistently and positively reviewed in the respective app stores, the overall number of reviews were limited. The reasons for this could be multifactorial. From the developer's perspective, they could perhaps do more to encourage users to submit reviews and feedback. From the user's perspective, providing feedback for a breast cancer app might be of low priority during a particularly stressful and uncertain period in their life. The use of app store reviews as a measure of meeting informational needs should be supported by other datapoints. This might include user focus groups or posts made on online breast cancer patient forums that reference the apps.

\section{Conclusions}

Becca and OWise are two breast cancer apps that score well on the MARS framework and address the needs of breast cancer patients after and during their treatment respectively. Both apps suffer from a lack of evidence to support their clinical effectiveness but aim to fill an informational needs gap that has been identified in the literature. As with many DHTs, particular attention should be paid to the handling of user data, to ensure it is compliant with national and international regulation and utilises suitable levels of encryption. More emphasis should also be placed on simple accessibility features to help ensure health apps are inclusive for different user groups. This study is based on the assessment of a single assessor. Future research should employ the use of multiple evaluators to validate the scores provided through the MARS framework and to allow more accurate comparison with the existing literature around breast cancer apps.

\section{Acknowledgments}

Funding: This work was supported by UK Research and Innovation (UKRI).

\section{Footnote}

Data Sharing Statement: Available at http://dx.doi. org/10.21037/mhealth-20-161

Conflicts of Interest: The author has completed the ICMJE uniform disclosure form (available at http://dx.doi. org/10.21037/mhealth-20-161). The author has no conflicts of interest to declare.

Ethical Statement: The author is accountable for all aspects of the work in ensuring that questions related to the accuracy or integrity of any part of the work are appropriately investigated and resolved.

Open Access Statement: This is an Open Access article distributed in accordance with the Creative Commons Attribution-NonCommercial-NoDerivs 4.0 International License (CC BY-NC-ND 4.0), which permits the noncommercial replication and distribution of the article with the strict proviso that no changes or edits are made and the original work is properly cited (including links to both the formal publication through the relevant DOI and the license). See: https://creativecommons.org/licenses/by-nc-nd/4.0/.

\section{References}

1. Bray F, Ferlay J, Soerjomataram I, et al. Global cancer statistics 2018: GLOBOCAN estimates of incidence and mortality worldwide for 36 cancers in 185 countries. CA Cancer J Clin 2018;68:394-424.

2. DeSantis C, Ma J, Bryan L, et al. Breast cancer statistics, 2013. CA Cancer J Clin 2014;64:52-62.

3. Cancer Research UK. Breast Cancer Statistics. 2020. Available online: https://www.cancerresearchuk.org/ health-professional/cancer-statistics/statistics-by-cancertype/breast-cancer

4. Forrest APM, Department of Health \& Social Security. Breast cancer screening: Report to the Health Ministers of England, Wales, Scotland and Northern Ireland. 3rd ed. London: H.M. Stationery Office, 1987:102.

5. NICE. Breast Cancer Quality Standard. 2011. Available online: www.nice.org.uk/guidance/qs12 
6. Department of Health \& Social Care. 2010 to 2015 government policy: cancer research and treatment. 2010. Available online: https://www.gov.uk/government/ publications/2010-to-2015-government-policy-cancerresearch-and-treatment/2010-to-2015-governmentpolicy-cancer-research-and-treatment

7. DoH, PHE, NHSE. Improving Outcomes: A Strategy for Cancer - Fourth Annual Report. 2014. Available online: https://assets.publishing.service.gov.uk/government/ uploads/system/uploads/attachment_data/file/213785/ dh_123394.pdf

8. Independent Cancer Taskforce. Acheiving World-Class Cancer Outcomes: A Strategy for England 2015-2020. Available online: https://www.cancerresearchuk.org/aboutus/cancer-strategy-in-england

9. Akshintala D, Chugh R, Amer F, et al. Nonalcoholic Fatty Liver Disease: The Overlooked Complication of Type 2 Diabetes 2000.

10. Abi Nader E, Kourie HR, Ghosn M, et al. Informational Needs of Women with Breast Cancer Treated with Chemotherapy. Asian Pac J Cancer Prev 2016;17:1797-800.

11. Sheehy EM, Lehane E, Quinn E, et al. Information Needs of Patients With Breast Cancer at Years One, Three, and Five After Diagnosis. Clin Breast Cancer 2018;18:e1269-75.

12. Sakai H, Umeda M, Okuyama H, et al. Differences in perception of breast cancer treatment between patients, physicians, and nurses and unmet information needs in Japan. Support Care Cancer 2020;28:2331-8.

13. O'Neill SC, Evans C, Hamilton RJ, et al. Information and support needs of young women regarding breast cancer risk and genetic testing: adapting effective interventions for a novel population. Fam Cancer 2018;17:351-60.

14. Danesh M, Belkora J, Volz S, et al. Informational needs of patients with metastatic breast cancer: what questions do they ask, and are physicians answering them? J Cancer Educ 2014;29:175-80.

15. Valero-Aguilera B, Bermúdez-Tamayo C, GarcíaGutiérrez JF, et al. Information needs and Internet use in urological and breast cancer patients. Support Care Cancer 2014;22:545-52.

16. Miyashita M, Ohno S, Kataoka A, et al. Unmet Information Needs and Quality of Life in Young Breast Cancer Survivors in Japan. Cancer Nurs 2015;38:E1-11.

17. Kemp E, Koczwara B, Butow P, et al. Online information and support needs of women with advanced breast cancer: a qualitative analysis. Support Care Cancer 2018;26:3489-96.

18. Vahabi M. Breast cancer and screening information needs and preferred communication medium among
Iranian immigrant women in Toronto. Health Soc Care Community 2011;19:626-35.

19. Vivar CG, McQueen A. Informational and emotional needs of long-term survivors of breast cancer. J Adv Nurs 2005;51:520-8.

20. Carr TL, Groot G, Cochran D, et al. Patient Information Needs and Breast Reconstruction After Mastectomy: A Qualitative Meta-Synthesis. Cancer Nurs 2019;42:229-41.

21. Lei CP, Har YC, Abdullah KL. Informational needs of breast cancer patients on chemotherapy: differences between patients' and nurses' perceptions. Asian Pac J Cancer Prev 2011;12:797-802.

22. Dawe DE, Bennett LR, Kearney A, et al. Emotional and informational needs of women experiencing outpatient surgery for breast cancer. Can Oncol Nurs J 2014;24:20-30.

23. Collins K, McClimens A, Mekonnen S, et al. Breast cancer information and support needs for women with intellectual disabilities: a scoping study. Psychooncology 2014;23:892-7.

24. Holden RJ, Kulanthaivel A, Purkayastha S, et al. Know thy eHealth user: Development of biopsychosocial personas from a study of older adults with heart failure. Int J Med Inform 2017;108:158-67.

25. Cooper A. The Inmates are Running the Asylum. Berkeley: Sams Publishing, 1999:17.

26. Pruitt J, Adlin T. The Persona Lifecycle: Keeping People in Mind Throughout Product Design. San Mateo, CA: Morgan Kaufmann Publishers, 2006:724.

27. van der Molen P, Maas AH, Chen W, et al. Identifying User Preferences for a Digital Educational Solution for Young Seniors With Diabetes. Diabetes Spectr 2017;30:182-7.

28. Vosbergen S, Mulder-Wiggers JM, Lacroix JP, et al. Using personas to tailor educational messages to the preferences of coronary heart disease patients. J Biomed Inform 2015;53:100-12.

29. Giunti G, Kool J, Rivera Romero O, et al. Exploring the Specific Needs of Persons with Multiple Sclerosis for mHealth Solutions for Physical Activity: Mixed-Methods Study. JMIR Mhealth Uhealth 2018;6:e37.

30. Calvillo-Arbizu J, Roa-Romero LM, Estudillo-Valderrama MA, et al. User-centred design for developing e-Health system for renal patients at home (AppNephro). Int J Med Inform 2019;125:47-54.

31. Wärnestål P, Svedberg P, Lindberg S, et al. Effects of Using Child Personas in the Development of a Digital Peer Support Service for Childhood Cancer Survivors. J Med Internet Res 2017;19:e161.

32. Ashmore LA, Stewart H, Hutton D, et al. Digital support 
for living with and beyond gynaecological cancer.

Radiography (Lond) 2020;26:e270-6.

33. Ricci A, Rochat J, Nap HH, et al. User-Centred Approach to Design an Online Social Support Platform for Seniors : Identification of Users' Types and Their Requirements. Stud Health Technol Inform 2020;270:1081-5.

34. Harder H, Holroyd P, Burkinshaw L, et al. A user-centred approach to developing bWell, a mobile app for arm and shoulder exercises after breast cancer treatment. J Cancer Surviv 2017;11:732-42.

35. Brennan L, Kessie T, Caulfield B. Patient Experiences of Rehabilitation and the Potential for an mHealth System with Biofeedback After Breast Cancer Surgery: Qualitative Study. JMIR Mhealth Uhealth 2020;8:e19721.

36. Brown W 3rd, Yen PY, Rojas M, et al. Assessment of the Health IT Usability Evaluation Model (Health-ITUEM) for evaluating mobile health (mHealth) technology. J Biomed Inform 2013;46:1080-7.

37. Holden RJ, Karsh BT. The technology acceptance model: its past and its future in health care. J Biomed Inform 2010;43:159-72.

38. Stoyanov SR, Hides L, Kavanagh DJ, et al. Mobile app rating scale: a new tool for assessing the quality of health mobile apps. JMIR Mhealth Uhealth 2015;3:e27.

39. APA. American Psychiatric Association. App Evaluation Model 2018. Available online: https://www.psychiatry. org/psychiatrists/practice/mental-health-apps/the-appevaluation-model

40. RankedHealth. RankedHealth. 2020. Available online: http://www.rankedhealth.com

41. MindTools. MindTools.io. 2020. Available online: https:// mindtools.io

42. One Mind. One Mind Psyber Guide. 2020. Available online: https://onemindpsyberguide.org/

43. Leigh S, Ouyang J, Mimnagh C. Effective? Engaging? Secure? Applying the ORCHA-24 framework to evaluate apps for chronic insomnia disorder. Evid Based Ment Health 2017;20:e20.

44. Torous J, Andersson G, Bertagnoli A, et al. Towards a consensus around standards for smartphone apps and digital mental health. World Psychiatry 2019;18:97-8.

45. Moshi MR, Tooher R, Merlin T. SUITABILITY OF CURRENT EVALUATION FRAMEWORKS FOR USE IN THE HEALTH TECHNOLOGY ASSESSMENT OF MOBILE MEDICAL APPLICATIONS: A SYSTEMATIC REVIEW. Int J Technol Assess Health Care 2018;34:464-75.

46. Carlo AD, Hosseini Ghomi R, Renn BN, et al. By the numbers: ratings and utilization of behavioral health mobile applications. NPJ Digit Med 2019;2:54.

47. Jeffrey B, Bagala $M$, Creighton A, et al. Mobile phone applications and their use in the self-management of Type 2 Diabetes Mellitus: a qualitative study among app users and non-app users. Diabetol Metab Syndr 2019;11:84.

48. Kalhori SRN, Hemmat M, Noori T, et al. Quality Evaluation of English Mobile Applications for Gestational Diabetes: App Review using Mobile Application Rating Scale (MARS). Curr Diabetes Rev 2021;17:161-8.

49. Siddique AB, Krebs M, Alvarez S, et al. Mobile Apps for the Care Management of Chronic Kidney and End-Stage Renal Diseases: Systematic Search in App Stores and Evaluation. JMIR Mhealth Uhealth 2019;7:e12604.

50. Amor-García MÁ, Collado-Borrell R, Escudero-Vilaplana $\mathrm{V}$, et al. Assessing Apps for Patients with Genitourinary Tumors Using the Mobile Application Rating Scale (MARS): Systematic Search in App Stores and Content Analysis. JMIR Mhealth Uhealth 2020;8:e17609.

51. Mandracchia F, Llauradó E, Tarro L, et al. Mobile Phone Apps for Food Allergies or Intolerances in App Stores: Systematic Search and Quality Assessment Using the Mobile App Rating Scale (MARS). JMIR Mhealth Uhealth 2020;8:e18339.

52. Martin Payo R, Fernandez Álvarez MM, Blanco Díaz M, et al. Spanish adaptation and validation of the Mobile Application Rating Scale questionnaire. Int J Med Inform 2019;129:95-9.

53. Knitza J, Tascilar K, Messner EM, et al. German Mobile Apps in Rheumatology: Review and Analysis Using the Mobile Application Rating Scale (MARS). JMIR Mhealth Uhealth 2019;7:e14991.

54. Stoyanov SR, Hides L, Kavanagh DJ, et al. Development and Validation of the User Version of the Mobile Application Rating Scale (uMARS). JMIR Mhealth Uhealth 2016;4:e72.

55. Young-Afat DA, van Gils CH, Bruinvels DJ, et al. Patients' and Health Care Providers' Opinions on a Supportive Health App During Breast Cancer Treatment: A Qualitative Evaluation. JMIR Cancer 2016;2:e8.

56. Giunti G, Giunta DH, Guisado-Fernandez E, et al. A biopsy of Breast Cancer mobile applications: state of the practice review. Int J Med Inform 2018;110:1-9.

57. Mobasheri MH, Johnston M, King D, et al. Smartphone breast applications - what's the evidence? Breast 2014;23:683-9.

58. Bender JL, Yue RY, To MJ, et al. A lot of action, but not in the right direction: systematic review and content 
analysis of smartphone applications for the prevention, detection, and management of cancer. J Med Internet Res 2013;15:e287.

59. Kalke K, Ginossar T, Bentley JM, et al. Use of EvidenceBased Best Practices and Behavior Change Techniques in Breast Cancer Apps: Systematic Analysis. JMIR Mhealth Uhealth 2020;8:e14082.

60. Ginossar T, Shah SF, West AJ, et al. Content, Usability, and Utilization of Plain Language in Breast Cancer

doi: $10.21037 /$ mhealth-20-161

Cite this article as: Wright A. Evaluation of two mobile health apps for patients with breast cancer using the Mobile Application Rating Scale. mHealth 2021;7:60.
Mobile Phone Apps: A Systematic Analysis. JMIR Mhealth Uhealth 2017;5:e20.

61. Orcha. Becca - Breast Cancer Support. 2020. Available online: https://appfinder.orcha.co.uk/search//?Page=0\&M inScore $=0 \&$ Days $=0 \&$ PageSize $=10 \&$ Keyword $=$ Pancreatic + Cancer $\& a c=\&$ SortBy $=\#$ details

62. Orcha. OWise breast cancer. 2020. Available online: https://appfinder.orcha.co.uk/ search//?keyword=Leukaemia 
Table S1 The full Mobile App Rating Scale results for Becca and OWise

\begin{tabular}{|c|c|c|}
\hline MARS item & Becca & OWise \\
\hline \multicolumn{3}{|l|}{ App classification } \\
\hline Version & 1.39 & 2.2 \\
\hline Last update & 3 Apr 2020 & 24 Oct 2020 \\
\hline Rating (current) & N/A & $N / A$ \\
\hline Rating (all) & iOS 4.5/5, Android 4.4/5 & iOS 4.7/5, Android 4.6/5 \\
\hline $\mathrm{N}$ ratings (current) & N/A & $\mathrm{N} / \mathrm{A}$ \\
\hline $\mathrm{N}$ ratings (all) & iOS 45, Android 78 & iOS 19, Android 18 \\
\hline Cost (basic) & Free & Free \\
\hline Cost (upgrade) & N/A & $\mathrm{N} / \mathrm{A}$ \\
\hline \multirow[t]{2}{*}{ Developer } & Breast Cancer Now & Px Healthcare Group Ltd \\
\hline & Super Being Labs & \\
\hline Platform & iOS \& Android & iOS \& Android \\
\hline Description & $\begin{array}{l}\text { An app that provides strategies, hints, and tips for } \\
\text { life after breast cancer treatment }\end{array}$ & $\begin{array}{l}\text { Provides personalised, safe, reliable, and credible } \\
\text { information as well as practical support and } \\
\text { guidance }\end{array}$ \\
\hline \multirow[t]{5}{*}{ Focus } & Happiness/wellbeing & Physical health \\
\hline & Mindfulness/meditation/relaxation & Sense of control \\
\hline & Relationships & \\
\hline & Physical Health & \\
\hline & Diet & \\
\hline \multirow[t]{3}{*}{ Theoretical background } & Information/education & Assessment \\
\hline & Advice/tips/strategies & Monitoring/tracking \\
\hline & Skills training & Personalisation \\
\hline Age group & Adults & Adults \\
\hline \multirow[t]{4}{*}{ Technical aspects } & Needs web access to function & Needs web access to function \\
\hline & & Allows password-protection \\
\hline & & Requires login \\
\hline & & Sends reminders \\
\hline Affiliations & Commercial & Commercial \\
\hline \multicolumn{3}{|l|}{ Section A: Engagement } \\
\hline 1. Entertainment & 3 & 5 \\
\hline 2. Interest & 4 & 5 \\
\hline 3. Customisation & 3 & 2 \\
\hline 4. Interactivity & 3 & 5 \\
\hline 5. Target group & 5 & 4 \\
\hline Engagement mean score & 3.6 & 4.2 \\
\hline \multicolumn{3}{|l|}{ Section B: Functionality } \\
\hline 6. Performance & 5 & 5 \\
\hline 7. Ease of use & 5 & 5 \\
\hline 8. Navigation & 5 & 5 \\
\hline 9. Gesture design & 5 & 5 \\
\hline Functionality mean score & 5 & 5 \\
\hline \multicolumn{3}{|l|}{ Section C: Aesthetics } \\
\hline 10. Layout & 5 & 4 \\
\hline 11. Graphics & 5 & 5 \\
\hline 12. Visual appeal & 4 & 5 \\
\hline Aesthetics mean score & 4.7 & 4.7 \\
\hline \multicolumn{3}{|l|}{ Section D: Information } \\
\hline 13. Accuracy & 5 & 5 \\
\hline 14. Goals & 3 & N/A \\
\hline 15. Quality of info & 5 & 5 \\
\hline 16. Quantity of info & 5 & 5 \\
\hline 17. Visual information & N/A & 5 \\
\hline 18. Credibility & 3 & 3 \\
\hline 19. Evidence base & N/A & 3 \\
\hline Information mean score & 4.2 & 4.3 \\
\hline \multicolumn{3}{|l|}{ Section E: Subjective quality } \\
\hline 20. Recommendation & 5 & 5 \\
\hline 21. Frequency of use & 5 & 5 \\
\hline 22. Value & 1 & 5 \\
\hline 23. Rating & 4 & 4 \\
\hline App subjective mean score & 4.38 & 4.75 \\
\hline App quality mean score & 4.38 & 4.55 \\
\hline
\end{tabular}

